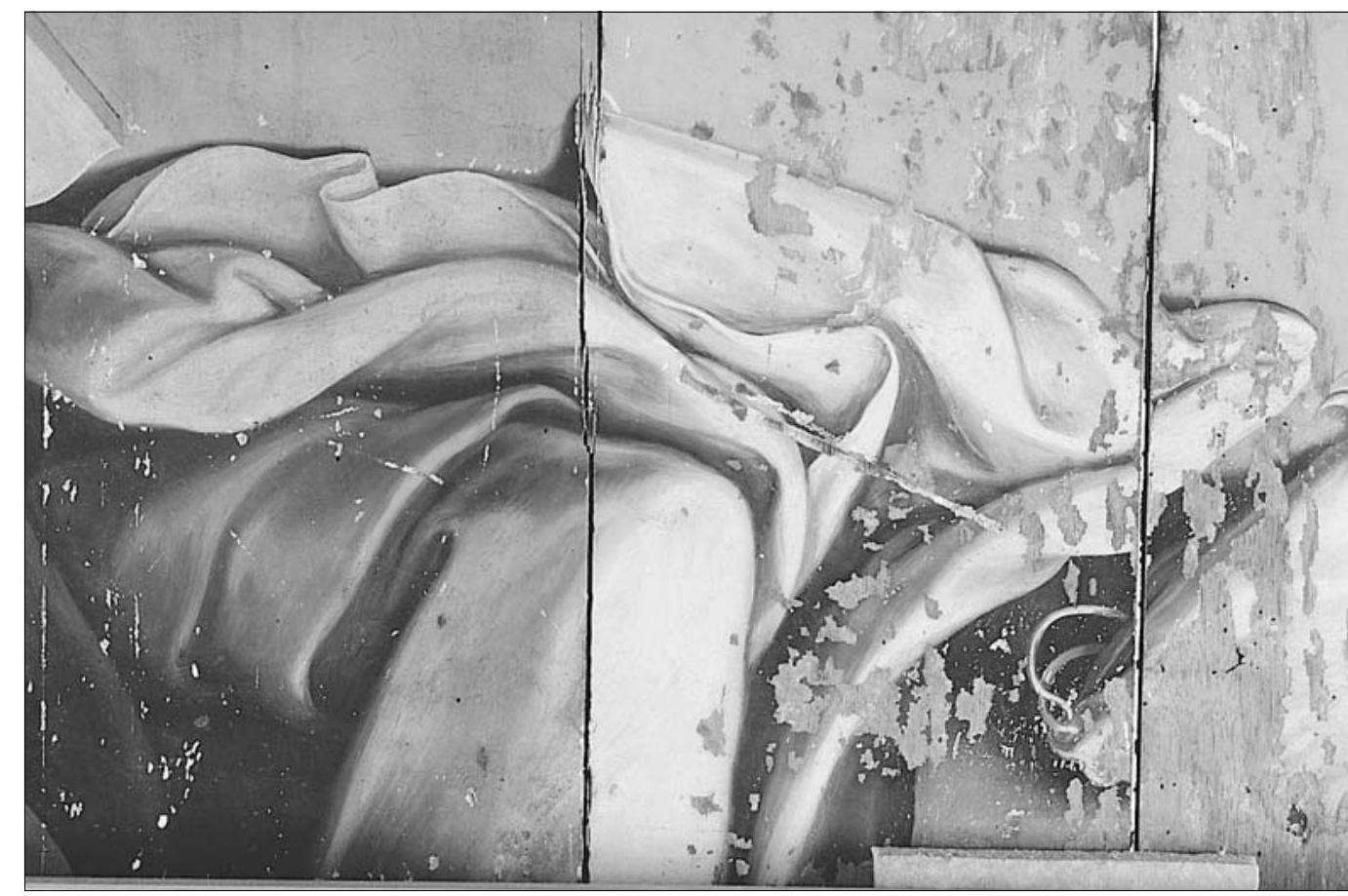

\title{
El concepto de pátina y la limpieza de pinturas
}

Paul Philippot 
Así los movimientos del soporte y el secado de la pintura provocan normalmente una red de craqueladuras, que juegan un rol, considerable en el aspecto de la textura de la obra. También el secado del aglutinante tiende a aumentar la transparencia de las capas pictóricas, especialmente en aquellas partes en las que el aglutinante ha sido utilizado en abundancia, como ocurre con las veladuras a base de tierras pardas, por efecto del incremento en ciertos casos de los contraste entre las zonas transparentes y la relativa opacidad de las zonas menos evolucionadas. Un fenómeno de este tipo se puede observar claramente en ciertas obras de Brouwer. Por otra parte, la evolución de ciertos colores es bien conocida. A menudo, se trata de un oscurecimiento, como sucede con algunos rojos o algunas sombras; el resinato de cobre tiende a oscurecerse; los azules presentan algunas veces una inestabilidad particular; los barnices amarillean y se reduce su transparencia. En fin, un fenómeno normal del secado es la exudación del aglutinante hacia la superficie. Esta migración contribuye, en gran medida, a determinar el lustre particular de la superficie pintada "estabilizada", y afecta, según el estado de la superficie, a la transparencia y a la profundidad de los tonos.

Sin embargo, todas estas modificaciones pueden ser consideradas como normales; salvo en casos extremos, en las que ni siquiera aparecen como alteraciones, sino como la simple marca del tiempo -con independencia de si, desde un punto de vista estrictamente material, se tratan evidentemente de procesos de alteración-.

Por otra parte, en la medida en la que estas modificaciones son irreversibles y escapan a una determinación rigurosa, hay que admitir que el estado original de la obra, es decir, aquel en el que el artista la ha dejado cuando acaba el proceso de creación, es completamente imposible de restablecer, al igual que de determinar objetivamente. Ninguna restauración podrá pretender jamás restablecer el estado original de una pintura. Sólo podrá revelar el estado actual de los materiales originales. Suponiendo que se desee, no se puede en ningún caso abolir la historicidad segunda de la obra: el tiempo que ha atravesado para llegar hasta nosotros.

Esta constatación nos permite abordar de manera más rigorosa el problema crítico, uniendo su aspecto histórico-estético a factores materiales en los que se concretiza. $Y$ es aquí donde tiene su sitio el concepto de pátina. La pátina, de hecho, es precisamente el efecto "normal" del paso del tiempo sobre la materia. No es un concepto físico ni químico, sino un concepto crítico. La pátina no es otra cosa que el conjunto de estas alteraciones "normales" en cuanto afectan el aspecto de la obra sin desfigurarla -precisamente porque se trata de alteraciones "normales"-. La noción misma de "normalidad" a la que hay que recurrir no descalifica en absoluto el concepto, pero revela simplemente que no concierne a la materia, sino que recurre al dominio crítico y supone siempre un juicio estético.

Sería un gran error creer que tal juicio pueda ser eliminado, y que esta eliminación pueda devolver el pro- blema a una objetividad "cientíica". En efecto, eliminar el problema de la pátina significaría simplemente plantear la cuestión desde un punto de vista material, y por consiguiente ignorar el hecho de la evolución de la materia -lo cual sería un error científico- o bien negarse a considerar el problema que plantea: las relaciones entre el estado original y el estado actual de las materias originales; es decir: renunciar a considerar la realidad estética de la obra de arte.

La importancia de la noción de pátina para la limpieza de las pinturas deriva del rol particular que desempeña el barniz. En efecto su brillo se atenúa con el paso del tiempo y esta alteración, siempre que no sobrepase ciertos límites, se combina con la de las capas subyacentes. En particular, cuando éstas han sufrido, puede atenuar los desgastes o los contrastes. De manera que se plantea necesariamente la cuestión de la evaluación del rol que juega o puede jugar la alteración del barniz en la constitución del aspecto actual de la obra. El estado actual de la capa pictórica no puede, en ningún caso, identificarse con el estado original de la obra; es indispensable, en el momento de la limpieza de la pintura, considerar el papel que juega o puede jugar el barniz como elemento de la pátina. Pero es evidente que esta apreciación, al igual que la de la pátina en general, está basada sobre una comparación mental del aspecto actual de la obra, -o con mayor exactitud, en los diferentes aspectos actuales posibles según el grado de limpieza- y de la idea que el restaurador se hace (y no puede tener más que una) de la imagen original. Tal comparación conlleva necesariamente una parte importante de hipótesis. Pero el restaurador no puede huir de ello y escaparse de su cometido. Es decir, ivolveríamos a caer en la pura subjectividad del gusto personal? .Éste sería el caso, sin duda, cada vez que se eluda el problema crítico, porque el restaurador no tome consciencia de ello y se deje guiar únicamente por sus preferencias personales; en este sentido, el desbarnizado completo puede no ser más que una manifestación de su gusto, al igual que el desbarnizado parcial. Su objetividad es, de hecho, ilusoria, ya que es el precio de la sustitución de un criterio puramente material por un juicio crítico.

Una metodología estríctamente crítica, por el contrario, exigirá una concienciación rigurosa de todos los aspectos del problema. Por una parte, será necesario estimar las alteraciones sufridas, tanto si se trata de una simple pátina o de auténticas desfiguraciones o desgastes: diagnóstico que se basa a la vez sobre el conocimiento objetivo de la evolución de las materias y sobre la idea que tenemos de su aspecto original, que responde a la experiencia de las obras en su realidad estética y material. Por otra parte, el restaurador deberá hacerse una idea lo más precisa posible de la unidad original de la obra en función de cada uno de sus valores particulares. Esta intuición, que es fundamental, no es otra cosa que la identificación de la realidad formal de la obra: ésta, al tener su propia coherencia es, de hecho, el único criterio con el que se pueden medir las alteraciones, siempre que afecten a la forma. Parece pues que se reduce a un círculo vicioso: la unidad de la obra se imagina a partir de la obra alterada, y las alteraciones apreciadas a partir de la unidad origi- 
nal. Pero así nos olvidamos de dos factores que salen del círculo vicioso y aseguran la validez del trabajo crítico: las alteraciones objetivamente demostrables, aunque sólo lo sean a nivel puramente material y la experiencia de la obra de arte como tal que, en razón misma a la coherencia formal que siempre presupone, denuncia también los daños que comporta -lo mismo que, con la experiencia, se pueden apreciar los eventuales errores en la ejecución de una pieza musical a través de dicha ejecución-.

La comparación entre el estado actual y la representación viva de la imagen original no es sólo posible, es la experiencia misma de la obra de arte como tal, en cuanto que ha llegado hasta nosotros a través del tiempo que nos separa de su creación. Es sobre esta base, hecha de un vaivén continuo de la materia a la imagen y de la imagen a la materia, con el que se precisa el diagnóstico crítico, en el que el restaurador podrá apreciar el papel desempeñado por las capas de barniz más o menos alteradas. La limpieza se convierte pues, desde el punto de vista crítico, en la búsqueda del equilibrio que es posible realizar actualmente para que resulte lo más fiel posible con la unidad original. Y es evidente que la solución siempre dependerá de cada caso concreto. La limpieza de una pintura nunca puede ser concebida como una operación puramente material y como tal "objetiva": la eliminación del barniz -y eventualmente de los repintes- que recubren la capa original. Limpiar una pintura se hace sobre la base de un conocimiento previo, el más exacto posible sobre su estado actual, para progresar hacia un estado que, sin dañar la materia original, restituya lo más fielmente posible la imagen original: progresión que implica en sumo grado la capacidad de prever, sin la cual es imposible pararse a tiempo, porque la limpieza se convierte en una búsqueda a ciegas de tesoros que se parará solamente -y no siempre- en la materia original.

De hecho, el velo que aporta el viejo barniz será generalmente muy valioso cuando se trata de compensar los contrastes acrecentados o de equilibrar partes usadas y partes intactas, mientras que la limpieza podrá hacerse normalmente con mayor profundidad cuando las alteraciones debidas a la pátina son mínimas. En este caso, sin embargo, habrá que tener en cuenta igualmente el hecho de que el desnudo radical de la capa pictórica original subraya casi siempre su materialidad en detrimento de la imagen y que, al otorgar un aspecto nuevo a un objeto antiguo, crea en su seno un desacuerdo que es una especie de falsificación; acentúa la materia en detrimento de la forma, y denuncia vis a vis en la obra de arte el predominio del interés higiénico del objeto sobre el interés estético de la imagen.

A medida que la limpieza se va acercando al desbarnizado completo, el estado de la superficie de la capa pictórica requiere evidentemente una atención creciente. El criterio de seguridad puramente material de la ausencia de pigmento sobre los algodones de disolvente no tiene evidentemente ningun valor, no solamente porque un control de este tipo sólo se puede hacer a posteriori y no constituye ninguna garantía, sino porque la superficie puede estar materialmente al- terada sin que se produzca pérdida de pigmentos. En efecto, la migración del aglutinante hacia la superficie durante el secado es determinante para la formación de su brillo, que confiere a los tonos su profundidad y su transparencia. Entonces, hay que admitir que el brillo puede estar alterado por una limpieza excesiva mucho antes de que éste aparezca con pérdida de pigmentos. De hecho, demasiado a menudo nos encontramos con cuadros estropeados por una limpieza drástica, que al alterar el brillo de la superficie, debido a la exudación del aglutinante, ha "desgastado la piel" de la pintura. Una llaga se abre entonces, donde el color aparece en la materialidad que tenía en la paleta, y se opone así a su propia transfiguración formal; la materia aflora en la imagen al igual que una isla surge de un lago y rompe la transparencia del agua. Son los efectos de la luz y de las partes claras las que padecen con mayor frecuencia estos estragos debido a la "búsqueda de un tesoro" de la materia original y algunos maestros se hallan, en consecuencia, particularmente expuestos a este peligro. El brillo fascinante de las pastas luminosas de Josse de Momper le han considerado desde hace mucho tiempo como víctima privilegiada, y muy pocas de sus obras han escapado de la masacre. Añadamos -porque nunca lo repetiremos lo suficiente- que el crimen se detiene entonces muy pocas veces en esta etapa. ¡Cuántas veces queremos exaltar más aún esta materia desnuda por un nuevo barnizado espeso y brillante como una carrocería! Esto es pues lo opuesto a una pátina, porque si ésta tranquiliza la materialidad de la pintura para subrayar la transposición de texturas en la imagen, el barniz rico y denso que envuelve la pintura más que cubrirla, interpone, por el contrario, la materialidad nueva y agresiva de su propia brillantez. Entonces nace un contraste entre la textura real de la pintura y el estado de su superficie que tiende a transformar la obra en su propia reproducción.

Deslizamiento bastante peligroso teniendo en cuenta la influencia creciente que ejerce las reproducciones en color, en papel couché, en el "museo imaginario" del público que acaba por exigir la conformidad de las obras con sus reproducciones.

El problema estético de la limpieza de las pinturas no se plantea en los términos abstractos de una alternativa: desbarnizado completo o parcial. Por el contrario consiste, tal y como hemos visto, en un desarrollo de interpretación crítica de cada caso, con el fin de restablecer, teniendo en cuenta el estado material actual de la obra, no el estado original ilusorio, un estado que sea lo más fiel posible a la unidad estética de la imagen original. A partir de este momento, podrán escalonarse según los casos soluciones concretas en toda la gama de grados de limpieza posibles hasta el desbarnizado completo. Sin embargo, en la práctica, es evidente que esta última fórmula sólo podrá ser justificada de manera excepcional, porque casi siempre aportará daños a la pátina al resaltar la materia en detrimento de la transfiguración formal de la imagen. 